\title{
UNIVERSALISTIC AND CULTURE-SPECIFIC PERSPECTIVES ON VARIATION IN THE ACQUISITION OF PRAGMATIC COMPETENCE IN A SECOND LANGUAGE
}

\author{
Ming-chung Yu
}

\section{INTRODUCTION}

The aim of this exploratory study is to examine the interlanguage behavior of Chinese ${ }^{2}$ learners of American English, focusing on the ways in which they make 'requests' in a second language (L2). This paper identifies the pragmatic difficulties that distinguish these learners' behavior from that of speakers of their target and native languages (L1), and discusses speech act performance from the perspectives of universality versus culture-specificity in speech act research.

Chinese and English are culturally and typologically very different languages. There are two reasons why English requests might constitute difficult forms for Chinese speakers to master. First, Chinese culture traditionally places a high value on communal needs over individual preferences. This generally makes Chinese think that in many situations where they ask for a favor, a direct, concise form such as 'Please take it for $m e$ ' can display their sincerity and politeness. However, this kind of direct request may be perceived as impolite or even rude by English speakers, in that politeness for them is basically associated with individual desires to act freely, and thus it is the indirect form like 'Could you take it for me?' that is considered appropriate (Brown \& Levinson, 1978, 1987). Second, English speakers can mitigate the imposing force of their requests by using past tense forms of verbs (e.g., 'I wanted to ...') or modal verbs (e.g., 'Could I...'), while there are no such parallel verbal devices in Chinese. Hence, for Chinese ESL learners who have not mastered these devices, their English requests with the 'Can I . . ' or 'I want ...' form might be seen as improper or impolite under some circumstances.

As requesting has been shown to be closely related to speakers' linguistic and cultural norms (e.g., Blum-Kulka, House, \& Kasper, 1989; Wierzbicka, 1991), Chinese learners' requestive behavior is worth studying in that it may be affected by their native language and culture so as to differ from that of English speakers. Also, research so far has rarely specifically focused on how Chinese make requests in their L2. We thus know very little about how Chinese learners may experience difficulties regarding the rules for performing this speech act. Hence, this study is designed to examine the L2 speech act behavior of an understudied group that typically has quite different cultural conventions from the Western.

\section{BACKGROUND}

\subsection{Theoretical Speech Act Studies}

The idea of speech acts was originally proposed by Austin (1962) as a tool for philosophical analysis. He introduces the idea that we can use words to do 
more than make statements of fact so that "to say something is to do something" (p. 12). Accordingly, in saying ' $I$ apologize', one is not only stating something, but performing an act of apology.

Searle (1969) further develops speech act theory by refining the structures of speech acts and the rules that govern their illocutionary force. He also proposes a distinction between direct speech acts, where speakers say what they mean, and indirect speech acts, where speakers mean more than, or something other than, what they say (1975). He focuses on the latter in detail, arguing that there are two types of indirectness in speech acts: nonconventional and conventional. The first involves utterances whose illocutionary force is not conventionally associated with any particular patterns so that it must be "calculated" (Grice, 1975, p. 50). For example, when X says to Y "Let's go to the movies tonight" (Searle, 1975, p. 61 ) and $Y$ replies "I have to study for an exam", $X$ has to go through a calculation process to reach the conclusion that Y's response is mainly intended to reject X's proposal, rather than asserting that $\mathrm{s} / \mathrm{he}$ has to study.

The second type concerns those whose force is conventionally associated with specific sentence patterns so that though their force can be calculated, such is not done. These utterances are indirect because they are conventionally meant to perform an action that is not most immediately suggested by their literal meaning. A number of scholars have argued that the chief motivation for using this type of indirectness is politeness, especially in requests (e.g., Searle, 1975; Brown \& Levinson, 1978, 1987; Leech, 1983). For example, the request 'Could you give me a hand?' is polite in at least two aspects: (i) the speaker does not presume to know about the hearer's ability; (ii) the hearer is given an option to refuse. Compliance can be thus made to appear to be a free act, instead of obeying a command.

As far as the performance of specific speech acts is concerned, the issue of universality (e.g., Austin, 1962; Searle, 1969, 1975) versus culture-specificity (e.g., Green, 1975; Wierzbicka, 1991) is still highly debated. Typical of this debate are the opposing views from Searle and Wierzbicka. Agreeing on Austin's claim that speech acts are semantic universals and are thus not culture-bound, Searle (1975) maintains that across languages and cultures, there are general norms for realizing speech acts and conveying politeness value, and that while the forms embodying these norms may vary from one language to another, the cross-cultural differences are not that important. However, Wierzbicka (1991), by providing examples from Polish and Japanese, objects to this universalistic stand and contends that speech act studies often suffer from an Anglo-Saxon ethnocentrism, arguing that under what conditions speech acts are to be performed is based on cultural norms, rather than certain general mechanisms. Given the relatively few languages studied, it is conceivable that the claim for universals is challenged by views like Wierzbicka's. By focusing on a understudied group whose cultural norms seem to very different from the Western, this study hopes to shed some light on this issue.

\subsection{Western and Chinese Concepts of Face and Politeness}

The main focus of this study is on the directness level of different speaker groups' request behavior. As noted above, indirectness has been claimed to be politeness-motivated. When it comes to politeness study, Brown and Levinson's $(1978,1987)$ theses can be seen as one of the most influential work for examining 
politeness phenomenon in human interaction. Based on the notion of face, they propose a universal theory of politeness, a sociolinguistic principle that guides a given speaker's language use in everyday discourse. Brown and Levinson believe that the speaker comes into any conversation with two "face wants" $(1987$, p. 13$)$ : "negative face" (p. 61) wants, which are the desires to act unimpeded by other people, and "positive face" wants, which are the desires to be liked by others. Ideally it is in everyone's best interests to honor others' desires, but practically, to satisfy one's needs frequently leads one to threaten others' face. They thus argue that some acts are intrinsically face-threatening and suggest that in carrying out "face-threatening acts" (FTAs) (p. 25), the speaker can do an act with redressive action, which attends to either the hearer's positive face (i.e., positive politeness) or negative face (i.e., negative politeness).

By contrast, although linguistic indirectness in Chinese is also driven by politeness concerns and thus serves as a face-redressive strategy (Zhang, 1995), the Chinese concept of face and politeness value is different from that of Western culture (Hu, 1944; Ho, 1975; Gu, 1990; Mao, 1994). According to Hu (1944), two aspects of face exist in Chinese. One, 'miànzi i' (面子), refers to an individual's need to abide by cultural norms and show one's desire to be part of the group; the other, 'liăn (脸)', refers to an individual's need to express one's moral sense about role and place. In practice, both aspects involve respectable and reputable images that one can claim for oneself from the community in which one interacts or to which one belongs (Ho, 1975), and are thus motivated through "a recognition by others of one's desire for social prestige, reputation, or sanction" (Hu, 1944, p. 47). That is, the dynamics of Chinese face is "an interactional orientation on the part of the individual speaker toward establishing connectedness to, and seeking interpersonal harmony with, one's own community" (Mao, 1994, p. 459).

Accordingly, Brown and Levinson's overall conceptualization of face is very different from that of Chinese. Brown and Levinson center their discussion on the individual aspect of face so as to conceive of face as an image intrinsically belonging to the 'self'. This self-image mainly concerns the individual's desires, and only to the extent that the self relies on others' face being maintained is this image public (Mao, 1994). Thus, to protect and enhance one's face is to act mainly in compliance with the anticipated expectations of personal desires, which are seen as rational assumptions that all members in the society are presumed to abide by.

In contrast, it is the harmony of individual behavior with the judgment of the community, rather than the accommodation of individual desires, that Chinese face emphasizes (Mao, 1994). In other words, for Chinese, one is presumed not to be motivated by a desire for freedom, but instead to seek the respect of the group. So Chinese face can be regarded as a public image that not only depends on but is determined by the participation of others. Consequently, the balance of face plays a crucial role in discourse in that giving face to others simultaneously helps one earn the recognition of the group, thus both protecting and enhancing one's own face (Zhang, 1995). In brief, Brown and Levinson's face is an individualistic, selforiented image, while Chinese face is a communal, interpersonal one.

As indirectness in both Chinese and English appears to be motivated by politeness, while politeness value and face semantics in the two are very different 
from each other, it would be interesting to see if indirectness functions differently as a face-redressive strategy for native Chinese and English speakers, and how it functions for Chinese L2 learners. This study is intended to address these issues.

\subsection{Research Questions}

This study was designed to examine the following research questions: (1) How does Chinese learners' English requestive behavior differ from that of native English speakers? Do their L2 request strategies and linguistic options resemble those of Chinese speakers in Chinese? (2) Are there differences in all subjects' requestive behavior across social constraints of 'distance' and 'dominance'?

\section{RESEARCH DESIGN}

\subsection{Subjects and Sampling Strategy}

Subjects in this study were three groups of college undergraduates: forty native Mandarin Chinese speakers provided the native Chinese data, forty native American English speakers provided the native English data, and the nonnative data came from forty native Chinese speakers who were ESL learners. They were all chosen from their native country, i.e., for both the native Chinese and learner groups, from Taiwan; for the native English group, from the U.S. For the nonnative data, as this study was to examine the pragmatic behavior of Chinese ESL learners in the Taiwanese educational system, those who had spent quite some time in the environment of the target language and culture (e.g., via study in the U.S.) were ruled out. For both sets of the native data, cross-cultural communication research (e.g., Gumperz, 1982; Clyne, Ball, \& Neil, 1991) has shown that under the influence of the target language and culture, proficient nonnative speakers, when using their L1, may no longer conform to their native norms. Thus, to ensure the reliability of both sets of L1 data, speakers outside their country of origin were not considered.

In Taiwan, English is a mandatory school subject that most undergraduates have taken for at least 7 years. To reduce possible effects from English, subjects for the native Chinese group were selected from students who had scored 525 or lower on the Test of English as a Foreign Language (TOEFL), reflecting a low-tomedium L2 proficiency. By contrast, subjects for the learner group were chosen from among students who had scored higher than 575 on the TOEFL, reflecting an intermediate-to-advanced L2 proficiency.

To achieve optimum comparability of the three subject groups so that the differences detected could not be attributed to variables other than those being studied, all subjects were given a background survey to insure that groups were as homogeneous as possible. The three groups did not differ in age, were from urban or suburban areas, and had college-educated parents; also, females and males were equally represented in each group.

\subsection{Method}

Data for this study were collected via a written questionnaire in the form of the 'Discourse Completion Task' (DCT) ${ }^{4}$. To avoid biasing the subjects' response 
choice, the word 'requests' was not mentioned throughout the descriptions in the DCT (Beebe \& Takahashi, 1989).

The questionnaire was designed to achieve systematic variation of two social factors - 'distance' and 'dominance' - which had both been shown to be important variables in determining speech act performance (Brown \& Levinson, 1978, 1987; Blum-Kulka, House, \& Kasper, 1989). Each variable was treated as binary-valued so that interlocutors either knew one another (-distance) or didn't know one another (+distance), and were either equal status (-dominance) or the listener was higher status (+dominance). The combination of these two variables resulted in four situations. Pilot testing had suggested that an individual's main request strategy was basically similar across situations with the same combination of distance and dominance, but to obtain more reliable data, the DCT included two situations for each variable combination. As successful speech act performance requires the internalization of contextual constraints, L2 learners must learn how to react to distinct situational tasks properly (Blum-Kulka, House, \& Kasper, 1989; Kasper \& Blum-Kulka, 1993). Thus, four different types of situational tasks, with two situations for each type, can provide a fuller picture of learners' behavior.

Since studies had shown that native speakers' intuitions about others' language use were often not reliable (Blom \& Gumperz, 1972; Wolfson, D'AmicoReisner, \& Huber, 1983), the situations constructed were designed to be culturally plausible for both Chinese and Americans so that subjects were not asked to report what they thought others would say. All situations had been discussed with a number of native Chinese and American college students, who confirmed that these situations were very likely to occur in their respective cultures and expressed that they could picture finding themselves in these situations. In addition, owing to the fact that it is difficult to find cross-culturally appropriate contexts in which undergraduates are socially dominant in both Taiwan and the U.S., the DCT did not include speaker-dominant situations. Simply put, in all situations subjects were placed in their own role, i.e., that of a student, to issue requests.

\subsection{Procedure}

There were two versions of the DCT in which the order of situations differed in order to avoid the potential effects of order of item administration. Each version had a parallel translation in both English and Chinese. The English questionnaire was given to native English speakers and ESL learners; the Chinese one was given to Chinese using Chinese.

\subsection{Coding Scheme and Measures}

Following Blum-Kulka and her colleagues' (1989, pp. 278 - 289) CCSARP project, this study identified for requests nine mutually exclusive strategies, which were later collapsed into three main categories: Direct, Conventionally Indirect, and Nonconventionally Indirect, and classified requestive modifiers in two main categories: Internal (i.e., downgraders) and External (i.e., supportive moves) ${ }^{5}$.

For strategies and modifiers respectively, the dependent variables were the main categories used by the subjects. Each of their responses was coded into one of these categories, and frequencies of responses within each main category was then obtained for each language group. 
The independent variables were the two binary-valued factors, distance and dominance, systematically varied in the questionnaire.

\subsection{Reliability of Coding}

Twenty percent of the data from each group were randomly selected to be independently coded by a second rater (Cohen, 1960). Both sets of English data were coded by a native American English speaker; the native Chinese data, by another native Chinese speaker. A correct-for-chance level of kappa of at least .85 was considered acceptable 6 .

\section{RESULTS 7}

\subsection{Strategies}

\section{- Quantitative Findings}

After the subjects' responses were classified into one of the three main strategies and then frequencies of responses within each main category were obtained for each subject group, a multivariate analysis of variance (ANOVA) with two repeated-measures within-subjects factors, 'distance' and 'dominance', and one between-subjects factor, 'group', was conducted to see whether there were significant differences in requestive behavior across groups and whether there were differences in all subjects' performance across these contextual variables. When a significant group by distance by dominance interaction was found, oneway ANOVAs were performed to see if there were significant group differences in the types of request produced to interlocutors varying along the dimensions of distance and dominance, and when a significant group effect was detected, a post hoc multiple comparison test employing the Tukey method was then conducted to determine which pairs of groups differed significantly.

Table 1 shows the distribution of the three main request strategies across all situations for the three subject groups.

Table 1. Percentage and raw frequencies of the three main strategies for the three subject groups.

\begin{tabular}{lccc}
\hline \multirow{2}{*}{ Request strategies } & \multicolumn{3}{c}{ Group } \\
\cline { 2 - 4 } & English & ESL & Chinese \\
\hline Direct & $\mathbf{0 . 0 1}$ ( $^{*}$ & $\mathbf{0 . 1 4}$ & $\mathbf{0 . 3 3}$ \\
& $(3)^{* *}$ & $(46)$ & $(104)$ \\
Conventionally Indirect & $\mathbf{0 . 8 7}$ & $\mathbf{0 . 8 4}$ & $\mathbf{0 . 6 3}$ \\
& $(277)$ & $(269)$ & $(201)$ \\
Nonconventionally Indirect & $\mathbf{0 . 1 3}$ & $\mathbf{0 . 0 2}$ & $\mathbf{0 . 0 5}$ \\
& $(40)$ & $(5)$ & $(15)$ \\
Totals & 100.00 & 100.00 & 100.00 \\
& $(320)$ & $(320)$ & $(320)$ \\
\hline
\end{tabular}

\footnotetext{
* All numbers were rounded to two decimals with the result that the total for a subject group might exceed 1.00 .

** The figures in parentheses indicate raw frequency.
} 
Figure 1 is a graphic representation of each group's overall performance of the three main strategies.
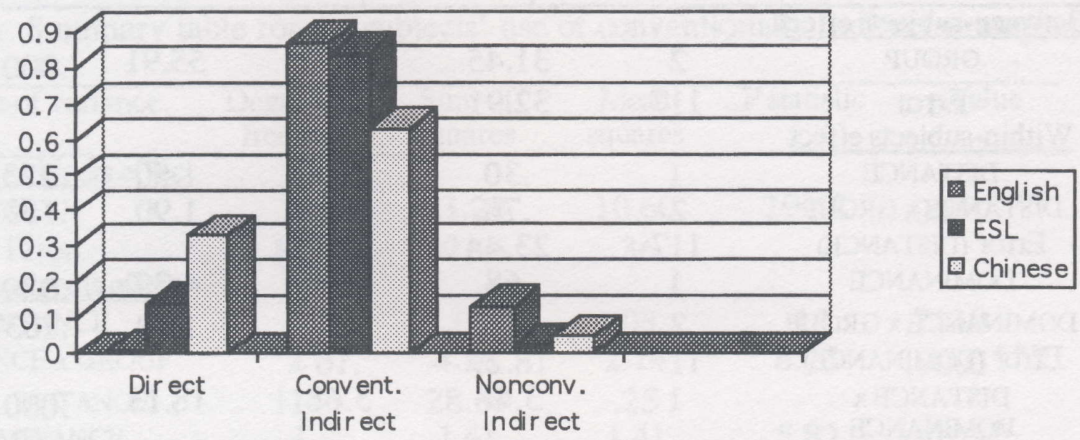

Figure 1. Graphic representation of proportion of the three main strategies used by three subject groups.

As Figure 1 shows, across all situations, conventionally indirect forms were preferred by speakers from all three groups; in addition, native Chinese speakers used the most direct strategies, while native English speakers employed the most conventionally and nonconventionally indirect strategies, and Chinese L2 learners were in-between in the use of both direct and conventionally indirect strategies and used the fewest nonconventionally indirect strategies.

\subsubsection{Direct strategies}

Analyses of variance were used to probe the effects of 'group', 'distance', and 'dominance' on the subjects' choice of direct strategies. Table 2 displays the results for all speakers' overall performance of these strategies.

As shown in Table 2, the three groups used direct strategies differently $(\mathrm{F}=$ 55.91, $\mathrm{p}<.0001$ ). Post hoc Tukey HSD tests indicated that Chinese speakers used significantly more direct forms than the other two groups, and that learners used more direct strategies than Americans ( $\mathrm{p}<.05)$.

In addition, subjects were found overall to be more likely to use a direct form in a hearer-dominant than in an equal-status situation $(\mathrm{F}=4.32, \underline{p}<.0399)$; however, Americans produced so few direct forms that this effect reflects only the preferences of the two Chinese groups. In contrast, speaker-hearer distance was not related to this choice $(\underline{F}=1.50, \mathrm{p}<.2235)$.

Furthermore, group differences were affected by the interaction of distance with dominance $(\mathrm{F}=5.21, \mathrm{p}<.0068)$. Specifically, Chinese speakers employed significantly more direct strategies than the other two groups in all four types of situations, whereas learners, except in -distance/-dominance situations, used more direct requests than Americans. Table 3 and Figure 2 summarize this interaction effect. 
Table 2. Summary table for the overall use of direct strategies by the three groups.

\begin{tabular}{|c|c|c|c|c|c|}
\hline Source of variance & $\begin{array}{l}\begin{array}{l}\text { Degrees of } \\
\text { freedom }\end{array} \\
\end{array}$ & $\begin{array}{l}\text { Sum of } \\
\text { squares }\end{array}$ & $\begin{array}{c}\text { Mean } \\
\text { squares }\end{array}$ & F statistic & $p$ value \\
\hline \multicolumn{6}{|l|}{ Between-subjects effect } \\
\hline GROUP & 2 & 31.45 & 15.73 & 55.91 & $.0001^{* * *}$ \\
\hline $\begin{array}{c}\text { Error } \\
\text { Within-subjects effect }\end{array}$ & 117 & 32.91 & .28 & & \\
\hline DISTANCE & 1 & .30 & .30 & 1.50 & .2235 \\
\hline DISTANCE $\times$ GROUP & 2 & .76 & .38 & 1.90 & .1537 \\
\hline Error (DISTANCE) & 117 & 23.44 & .20 & & \\
\hline DOMINANCE & 1 & .68 & .68 & 4.32 & $.0399^{*}$ \\
\hline DOMINANCE $\mathrm{x}$ GROUP & 2 & .54 & .27 & 1.72 & .1837 \\
\hline Error (DOMINANCE) & 117 & 18.29 & .16 & & \\
\hline DISTANCE $x$ & 1 & 3.68 & 3.68 & 18.13 & $.0001^{* * *}$ \\
\hline $\begin{array}{l}\text { DOMINANCE } \\
\text { DISTANCE } x\end{array}$ & 2 & 2.11 & 1.06 & 5.21 & $.0068^{* *}$ \\
\hline $\begin{array}{l}\text { DOMINANCE x GROUP } \\
\text { Error (DISTANCE x } \\
\text { DOMINANCE) }\end{array}$ & 117 & 23.71 & .20 & & \\
\hline
\end{tabular}

Table 3. Summary table of the distance by dominance effect on the differences of the three groups' use of direct strategies.

\begin{tabular}{ccccc} 
& & English & ESL & Chinese \\
\hline DISTANCE & DOMINANCE & & & \\
+ & + & $.00(\mathrm{C})^{*}$ & $.14(\mathrm{~B})$ & $.31(\mathrm{~A})$ \\
& - & $.01(\mathrm{C})$ & $.15(\mathrm{~B})$ & $.43(\mathrm{~A})$ \\
\hline- & + & $.01(\mathrm{C})$ & $.23(\mathrm{~B})$ & $.39(\mathrm{~A})$ \\
& - & $.01(\mathrm{~B})$ & $.06(\mathrm{~B})$ & $.18(\mathrm{~A})$
\end{tabular}

* Means with the same letter are not significantly different.

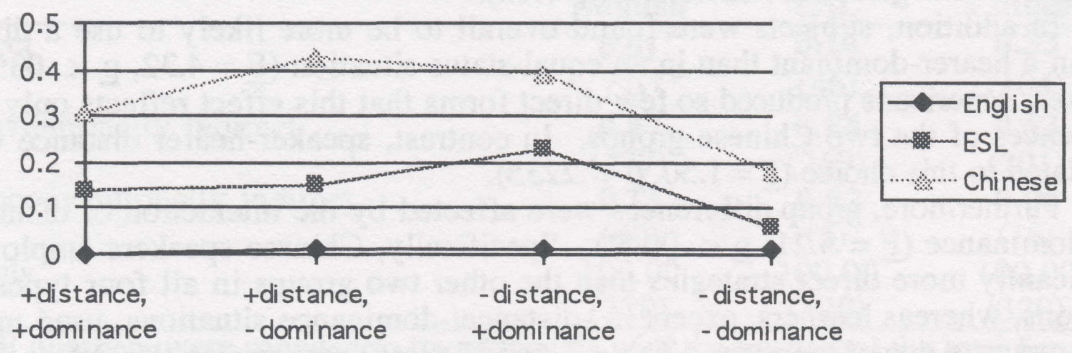

Figure 2. Rate of choice of direct forms by group and speaker-listener attributes. 


\subsubsection{Conventionally indirect strategies}

Analyses of variance were also employed to examine the subjects' choice of conventionally indirect forms. Table 4 summarizes these results.

Table 4. Summary table for the subjects' use of conventionally indirect strategies.

\begin{tabular}{|c|c|c|c|c|c|}
\hline Source of variance & $\begin{array}{c}\text { Degrees of } \\
\text { freedom }\end{array}$ & $\begin{array}{l}\text { Sum of } \\
\text { squares }\end{array}$ & $\begin{array}{c}\text { Mean } \\
\text { squares }\end{array}$ & F statistic & pvalue \\
\hline \multicolumn{6}{|c|}{ Between-subjects effect } \\
\hline GROUP & 2 & 21.20 & 10.60 & 29.42 & $.0001^{* * *}$ \\
\hline \multirow{2}{*}{\multicolumn{6}{|c|}{ Within-subjects effect }} \\
\hline & & & & & \\
\hline DISTANCE & 1 & .03 & .03 & .14 & .7130 \\
\hline DISTANCE $x$ GROUP & 2 & 4.28 & 2.14 & 8.73 & $.0003^{* * *}$ \\
\hline Error (DISTANCE) & 117 & 28.69 & .25 & & \\
\hline DOMINANCE & 1 & 1.41 & 1.41 & 5.83 & $.0174 *$ \\
\hline DOMINANCE $\mathrm{x}$ GROUP & 2 & 1.30 & .65 & 2.70 & .0716 \\
\hline Error (DOMINANCE) & 117 & 28.29 & .24 & & \\
\hline DISTANCE $x$ & 1 & .41 & .41 & 1.37 & .2435 \\
\hline $\begin{array}{l}\text { DOMINANCE } \\
\text { DISTANCE } \mathrm{x}\end{array}$ & 2 & 1.83 & 91 & 3.08 & $0498^{*}$ \\
\hline DOMINANCE $\mathrm{x}$ GROUP & & & & & \\
\hline $\begin{array}{l}\text { Error (DISTANCE x } \\
\text { DOMINANCE) }\end{array}$ & 117 & 34.76 & .30 & & \\
\hline
\end{tabular}

As Table 4 shows, the three groups used conventionally indirect strategies differently $(\underline{F}=29.42, \underline{p}<.0001)$. Post hoc tests using the Tukey method showed that both Americans and L2 learners employed significantly more conventionally indirect forms than Chinese speakers $(\mathrm{p}<.05)$. Additionally, speakers were found overall to be more likely to choose a conventionally indirect form with an equalstatus hearer such as a peer than with a higher-status listener like a professor $(\mathrm{F}=$ $5.83, \mathrm{p}<.0174)$. The use of this type of strategy was not related, however, to whether the hearer was familiar or not $(\underline{F}=.14, \underline{p}<.7130)$.

Table 5. Summary table of the distance by dominance effect on the differences of the three groups' choice of conventionally indirect strategies.

DISTANCE

English

ESL

Chinese

\begin{tabular}{ccccc} 
DISTANCE & DOMINANCE & & & \\
+ & + & $.90(\mathrm{~A})^{*}$ & $.83(\mathrm{~A})$ & $.55(\mathrm{~B})$ \\
& - & $.94(\mathrm{~A})$ & $.85(\mathrm{~A})$ & $.58(\mathrm{~B})$ \\
\hline & + & $.85(\mathrm{~A})$ & $.78(\mathrm{~A})$ & $.60(\mathrm{~B})$ \\
$*$ Means with the same letter are not significantly different. & $.79(\mathrm{~A})$ & $.79(\mathrm{~A}, \mathrm{~B})$
\end{tabular}


Moreover, group differences were affected by the interaction of distance with dominance $(\underline{F}=3.08, \underline{p}<.0498)$. Specifically, both Americans and ESL learners more often used conventionally indirect strategies than Chinese speakers in +distance/+dominance, +distance/-dominance, and-distance/+dominance situations, while in -distance/-dominance situations learners more often used these strategies than Americans. Table 5 and Figure 3 summarize this interaction effect.

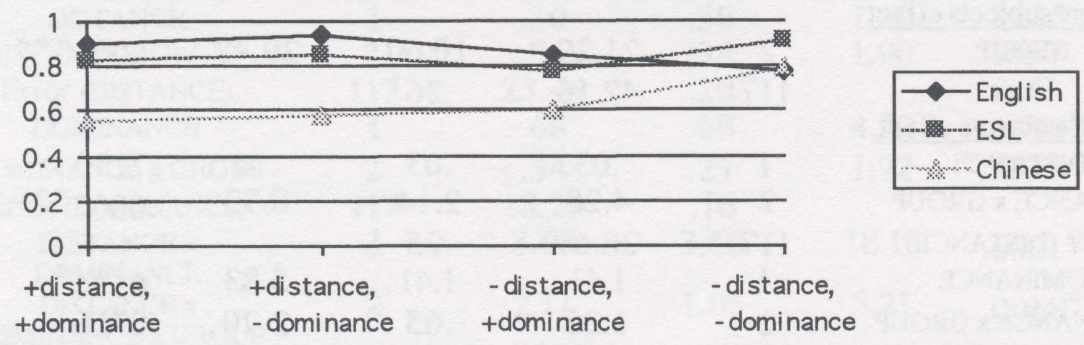

Figure 3. Rate of choice of conventionally indirect forms by group and speakerlistener attributes.

\subsubsection{Nonconventionally indirect strategies}

Analyses of variance were again used to investigate the subjects' use of nonconventionally indirect forms. Table 6 summarizes these results.

Table 6. Summary table for the subjects' use of nonconventionally indirect forms.

\begin{tabular}{|c|c|c|c|c|c|}
\hline Source of variance & $\begin{array}{l}\text { Degrees of } \\
\text { freedom }\end{array}$ & $\begin{array}{l}\text { Sum of } \\
\text { squares }\end{array}$ & $\begin{array}{c}\text { Mean } \\
\text { squares }\end{array}$ & F statistic & p value \\
\hline \multicolumn{6}{|l|}{ Between-subjects effect } \\
\hline GROUP & 2 & 4.06 & 2.03 & 22.77 & $.0001^{* * *}$ \\
\hline $\begin{array}{c}\text { Error } \\
\text { Within-subiects effect }\end{array}$ & 117 & 10.44 & .09 & & \\
\hline DISTANCE & 1 & .13 & .13 & 1.19 & .2772 \\
\hline DISTANCE $\mathrm{x}$ GROUP & 2 & 1.78 & .89 & 7.95 & $.0006^{* * *}$ \\
\hline Error (DISTANCE) & 117 & 13.09 & .11 & & \\
\hline DOMINANCE & 1 & .13 & .13 & 1.16 & .2839 \\
\hline DOMINANCE $x$ GROUP & 2 & .40 & .20 & 1.76 & .1772 \\
\hline Error (DOMINANCE) & 117 & 13.46 & .12 & & \\
\hline DISTANCE $\mathrm{x}$ & 1 & 1.63 & 1.63 & 14.52 & $.0002^{* * *}$ \\
\hline $\begin{array}{l}\text { DOMINANCE } \\
\text { DISTANCE } \mathbf{x}\end{array}$ & 2 & 1.86 & .93 & 3.11 & $.0464^{*}$ \\
\hline $\begin{array}{l}\text { DOMINANCE x GROUP } \\
\text { Error (DISTANCE x } \\
\text { DOMINANCE) }\end{array}$ & 117 & 13.16 & .11 & & \\
\hline
\end{tabular}


As displayed in Table 6, all groups employed nonconventionally indirect strategies differently $(\underline{F}=22.77, \underline{p}<.0001)$. Post hoc Tukey HSD tests revealed that Americans used significantly more nonconventionally indirect forms than both learners and Chinese speakers $(\mathrm{p}<.05)$.

In addition, group differences were affected by the interaction of distance with dominance $(\underline{F}=3.11, \underline{p}<.0464)$. Specifically, English speakers, except in +distance/+dominance, employed significantly more nonconventionally indirect strategies than both learners and native Chinese speakers. Table 7 and Figure 4 summarize this interaction effect.

Table 7. Summary table of the distance by dominance effect on the differences of the three groups' use of nonconventionally indirect strategies.

\begin{tabular}{ccccc} 
& & English & ESL & Chinese \\
\hline DISTANCE & DOMINANCE & & & \\
& + & $.10(\mathrm{~A})^{*}$ & $.08(\mathrm{~A})$ & $.14(\mathrm{~A})$ \\
& - & $.05(\mathrm{~A})$ & $.00(\mathrm{~B})$ & $.00(\mathrm{~B})$ \\
\hline & + & $.14(\mathrm{~A})$ & $.00(\mathrm{~B})$ & $.01(\mathrm{~B})$ \\
$*$ Means with the same letter are not significantly different. & $.03(\mathrm{~B})$
\end{tabular}

* Means with the same letter are not significantly different.

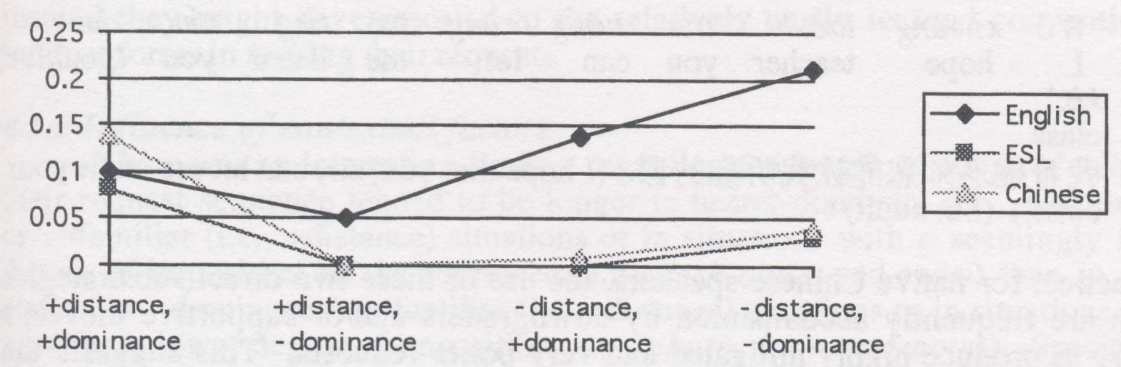

Figure 4. Rate of choice of nonconventionally indirect strategies by group and speaker-listener attributes.

\section{- Qualitative Analyses}

When all groups' requests were examined, we could further find out in what respect they differed from one another and if learners' behavior approached the native English norms or more closely resembled that of Chinese speakers.

\subsubsection{Performance of direct strategies}

The quantitative findings above appear to suggest that ESL learners' use of direct forms did not approximate that of English speakers and might reflect the influence of L1 strategies. The qualitative examination of subjects' responses 
confirms this supposition. For example, all learners' direct requests were issued through 'performative' and 'want statement' substrategies (with 22 and 24 cases respectively), with tag structures attached sometimes, such as

(1) 'I'd like to ask you a favor, is it alright?' (S7: study) ${ }^{8}$

and

(2) 'I hope you can let me take the exam some other time' (S5: exam)

These two substrategies were rarely used by Americans with only 1 case:

(3) 'I'd like to audit your class, is that all right?' (S6: audit)

However, they were used in all direct strategies by Chinese speakers (with 60 performatives and 44 want statements) like

(4) 'Wǒ xǐang qǐng nín bāng wǒmen zhaòxìng, haǒ mā?' I want ask you help us take photos, okay (question) 我想请您帮我们照相好吗? (I'd like to ask you to take a picture for us, is it O.K.?) (S4: photo)

and

$$
\begin{aligned}
& \text { 'Wǒ xīwàng laǒshī nín nĕng ràng wǒ tīng nín de } \\
& \text { I hope teacher you can let me listen you (genitive) } \\
& \text { kè.' } \\
& \text { class } \\
& \text { 我希望老师您能让我听您的课. (I hope that you, sir, can let me audit your } \\
& \text { class.) (S6: audit) }
\end{aligned}
$$

In practice, for native Chinese speakers, the use of these two direct substrategies, which are frequently accompanied by downgraders and/or supportive moves, is usually to produce highly mitigated and very polite requests. This suggests that Chinese ESL learners might appropriate politeness strategies from their L1, and, in effect, translate these into English forms that were rarely used by Americans.

\subsubsection{Performance of conventionally and nonconventionally indirect strategies}

Although learners produced a percentage of conventionally indirect forms similar to the Americans', there existed a substantial difference between these two groups' nonconventionally indirect behavior. There are two interesting issues here. First, did learners' use of conventional indirectness approximate that of the Americans qualitatively? Second, did the forms of learners' conventionally and nonconventionally indirect requests, like their direct ones, reflect L1 strategies?

For the first issue, learners' responses, compared to those of the Americans, did not appear to approach the English norms. For example, seldom did learners 
use the past tense forms of verbs (e.g., 'I wondered . . .') or modal verbs (e.g., 'Could I ...') to soften the imposing force of their requests, but Americans often employed these devices in their requests. As compared to a Slavonic or Romance language, Chinese has a simple internal structure of words, with only very few inflectional morphemes indicating categories like tense/aspect and number/person for verbs, or categories such as case and gender for nouns. This may explain Chinese ESL learners' difficulty in learning how to make use of devices such as past tense or modal verbs in appropriate contexts to mitigate their requests. Also, learners' relatively rare use of these devices in L2 may have reflected lack of L1 experience with modality or tense shifts as resources for politeness.

For the second issue, on the one hand, the result that Chinese speakers had the lowest percentage of conventionally indirect strategies might suggest that learners' great preference for using them had little to do with the existence of these forms in their L1 repertoires. However, due to the fact that these strategies are very common in both Chinese and English, it may be possible that learners' experience with similar forms in their L1 meant they had little difficulty learning how to use these strategies to issue requests in L2. On the other hand, as nonconventionally indirect strategies depend heavily on context and do not have obvious features that can be generalized from their surface forms, it is not easy for us to determine if learners' performance drew upon L1 strategies. One possible explanation is that while learners' use of few hints might have reflected L1 communicative style (i.e., ESL learners, like native Chinese speakers, might prefer to avoid employing these strategies), it is also likely that they still had not acquired adequate sociopragmatic and pragmalinguistic abilities to use nonconventional indirectness at discretion, so instead they might have resorted to the relatively easily learned conventionally indirect forms in making their requests.

\subsubsection{Influence of contextual factors}

There was an interesting finding regarding the length of subjects' requests: their request sequence tended to be longer in hearer-dominant (i.e., +dominance) or unfamiliar (i.e., +distance) situations or in situations with a seemingly higher degree of imposition on the addressee (e.g., desk, class, and exam) than in equalstatus (i.e., -dominance) or familiar (i.e., -distance) situations or in situations with a seemingly lower degree of imposition (e.g., photo, door, and notes). Specifically, the requests in the former situations were often modified by downgraders and/or supportive moves, while the requests in the latter were typically modified only by downgraders. This phenomenon was striking for native Chinese speakers' direct requests; also, in hearer-dominant, unfamiliar, or higher imposition situations, the use of downgraders and supportive moves by them usually accompanied want statements, whereas in equal-status, familiar, or lower imposition situations, the use of downgraders frequently accompanied performatives. For example:

'Máfán nǐ bāng wǒmen zhaò zhāng xiàng.'
bother you help us take (classifier) picture
麻烦你帮我们照张相. (I'd like you to take a picture for us, please.)

(S4: photo, an equal-status, familiar, or lower imposition situation) 
(7)

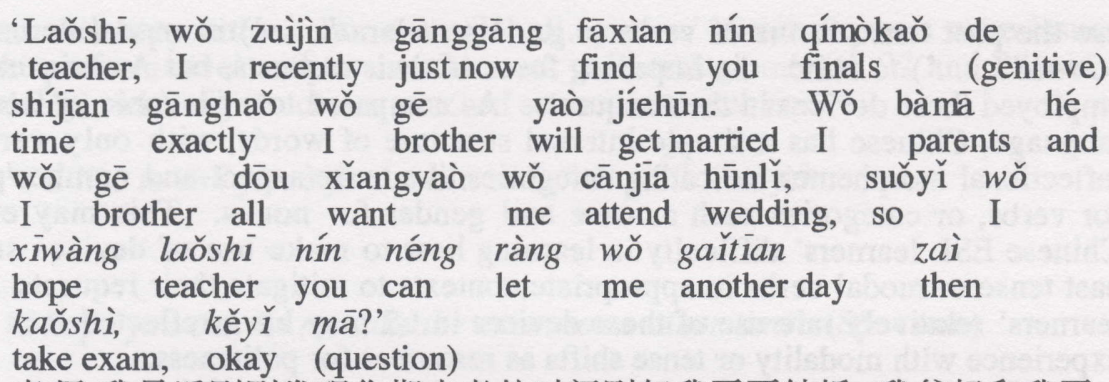
老师,我最近刚刚发现您期末考的时间刚好我哥要结婚. 我爸妈和我哥 都想要我参加婚礼,所以我希望老师您能让我改天再考试, 可以吗? (Sir, I have just learned recently that the scheduled time of your finals happens to be the same as that of my brother's wedding. My parents and brother all want me to attend the wedding, so I hope that you can let me take the exam on another day, is that all right?) (S5: exam, a hearer-dominant, unfamiliar, or higher imposition situation)

The finding that all three speaker groups' request sequences tended to be embedded with downgraders and/or supportive moves in hearer-dominant or unfamiliar situations, or in situations where the degree of imposition seemed to be high seems to lend support to Brown and Levinson's $(1978,1987)$ claim that in many and perhaps all cultures, dominance, distance, and ranking of imposition affect the speaker's performance of a face-threatening act. In fact, other factors such as request goals and interlocutors' rights and obligations may also play a crucial role in requestive behavior (Blum-Kulka, House, \& Kasper, 1989; Kasper \& Dahl, 1991). Take Situation 7 and 8 for example. Although the social relations in these two situations were designed to be familiar and equal-status, the fact that in Situation 7, the speaker, compared to the addressee, appears to be incompetent in terms of academic work creates a new social relationship in which dominance is in effect asymmetrical. Seen from this light, Situation 7 is different from 8 because asking for notes does not put oneself in a subordinate situation, whereas asking for tutoring appears to do so. Hence, responses between this pair seemed to be more discrepant than those between the other pairs.

In general, the quantitative results and qualitative analyses above showed that ESL learners' requestive behavior did differ from that of English speakers, especially in learners' choice of direct and nonconventionally indirect strategies, and that learners' behavior in L2 did appear to resemble their L1, especially for direct forms. In addition, subjects did differ in their strategy use across contextual factors of 'distance' and 'dominance', and these two variables and/or others seemed to affect their requestive performance.

\subsection{Internal and External Modifiers}

- Quantitative Findings

After the modifiers used by the subjects to mitigate the level of imposition of their requests were identified as either internal (i.e., downgraders) or external (i.e., 
supportive moves), the frequencies of modifiers within each main category were obtained for each group. Then, again, a multivariate approach to conducting a repeated-measures analysis was used to see if there were significant differences in modifier use across groups and in subjects' behavior across social factors, and oneway ANOVAs and post hoc Tukey tests were further performed where necessary.

Table 8 shows the distribution of internal and external modifiers across all situations for the three subject groups.

Table 8. Percentage and raw frequencies of internal and external modifiers per request across all situations for the three speaker groups.

\begin{tabular}{lcccccc}
\hline & \multicolumn{2}{c}{ English } & \multicolumn{2}{c}{ ESL } & \multicolumn{2}{c}{ Chinese } \\
\cline { 2 - 7 } Situation 1-8 & Downgraders & Supp. Moves & Downgraders & Supp. Moves & Downgraders & Supp. Moves \\
\hline Totals & .71 & 1.00 & .58 & 1.21 & 1.25 & .92 \\
& $(228)^{*}$ & $(319)$ & $(186)$ & $(387)$ & $(401)$ & $(295)$ \\
\hline
\end{tabular}

* The figures in parentheses indicate raw frequency.

Figure 5 is a graphic representation of modifier frequency distribution per request for each group.

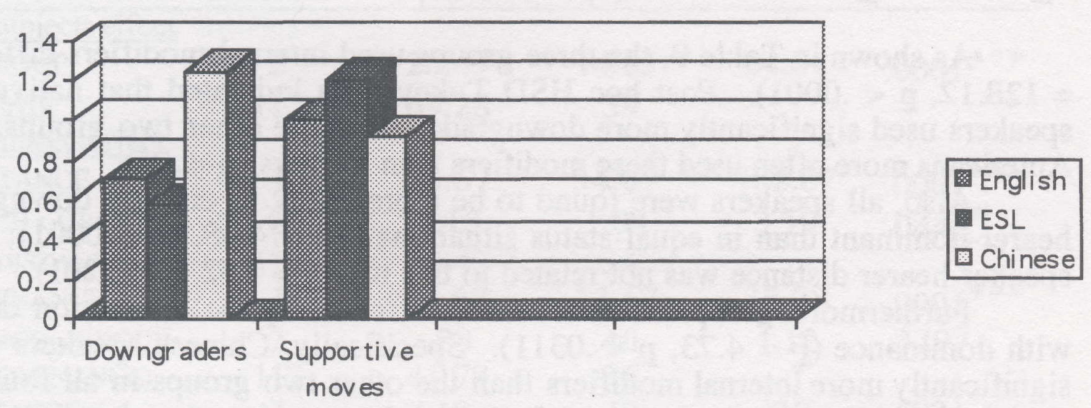

Figure 5. Graphic representation of modifiers per request for the three groups.

As Table 8 and Figure 5 indicate, across all situations, (i) Chinese speakers employed the most downgraders per request, while learners used the fewest and Americans were in-between; (ii) learners employed the most supportive moves per request, whereas Chinese speakers used the fewest and Americans were again inbetween; (iii) while Chinese speakers used more internal than external modifiers, both Americans and learners employed more external than internal modifiers.

\subsubsection{Internal modifiers}

Analyses of variance were used to detect the effects of 'group', 'distance', and 'dominance' on the subjects' use of internal modification. Table 9 displays the results for all speakers' overall performance of downgraders. 
Table 9. Summary table for the overall use of downgraders by the three groups.

\begin{tabular}{cccccc}
\hline Source of variance & $\begin{array}{c}\text { Degrees of } \\
\text { freedom }\end{array}$ & $\begin{array}{c}\text { Sum of } \\
\text { squares }\end{array}$ & $\begin{array}{c}\text { Mean } \\
\text { squares }\end{array}$ & F statistic & p value \\
\hline Between-subjects effect & 2 & 162.33 & 81.16 & 128.12 & $.0001^{* * *}$ \\
\hline GROUP & 117 & 74.12 & .63 & & \\
Error & 1 & .60 & .60 & 1.52 & .2201 \\
Within-subjects effect & 1.30 & .65 & 1.65 & .1972 \\
\hline DISTANCE & 2 & 46.34 & .40 & & \\
DISTANCE x GROUP & 117 & 26.60 & 26.60 & 74.38 & $.0001^{* * *}$ \\
Error (DISTANCE) & 1 & 2.80 & 1.40 & 3.92 & $.0225^{*}$ \\
DOMINANCE & 2 & 41.84 & .36 & & \\
DOMINANCE x GROUP & 117 & 1.10 & 1.10 & 4.43 & $.0375^{*}$ \\
Error (DOMINANCE) & 1 & 2.62 & 1.31 & 4.73 & $.0311^{*}$ \\
DISTANCE $\mathrm{x}$ & 2 & 29.19 & .25 & & \\
DOMINANCE & & & & & \\
DISTANCE $\mathrm{x}$ & 117 & & & &
\end{tabular}

As shown in Table 9, the three groups used internal modifiers differently ( $\mathrm{F}$ $=128.12, \mathrm{p}<.0001)$. Post hoc HSD Tukey tests indicated that native Chinese speakers used significantly more downgraders than the other two groups, and that Americans more often used these modifiers than learners $(\mathrm{p}<.05)$.

Also, all speakers were found to be more likely to employ downgraders in hearer-dominant than in equal-status situations $(\mathrm{F}=74.38, \mathrm{p}<.0001)$; however, speaker-hearer distance was not related to this use $(\mathrm{F}=1.52, \underline{\mathrm{p}}<.2201)$.

Furthermore, group differences were affected by the interaction of distance with dominance $(\mathrm{F}=4.73, \mathrm{p}<.0311)$. Specifically, Chinese speakers employed significantly more internal modifiers than the other two groups in all four types of situations, while Americans more often used downgraders than learners in familiar situations. Table 10 and Figure 6 summarize this interaction effect.

Table 10. Summary table of the distance by dominance effect on the differences of the three groups' use of internal modifiers.

English

ESL

Chinese

\begin{tabular}{ccccc}
\hline DISTANCE & DOMINANCE & & & \\
& + & $.83(\mathrm{~B})^{*}$ & $.68(\mathrm{~B})$ & $1.28(\mathrm{~A})$ \\
+ & - & $.54(\mathrm{~B})$ & $.53(\mathrm{~B})$ & $1.15(\mathrm{~A})$ \\
\hline & + & $.91(\mathrm{~B})$ & $.75(\mathrm{C})$ & $1.36(\mathrm{~A})$ \\
$*$ & & $.58(\mathrm{~B})$ & $.38(\mathrm{C})$ & $1.23(\mathrm{~A})$ \\
& & &
\end{tabular}




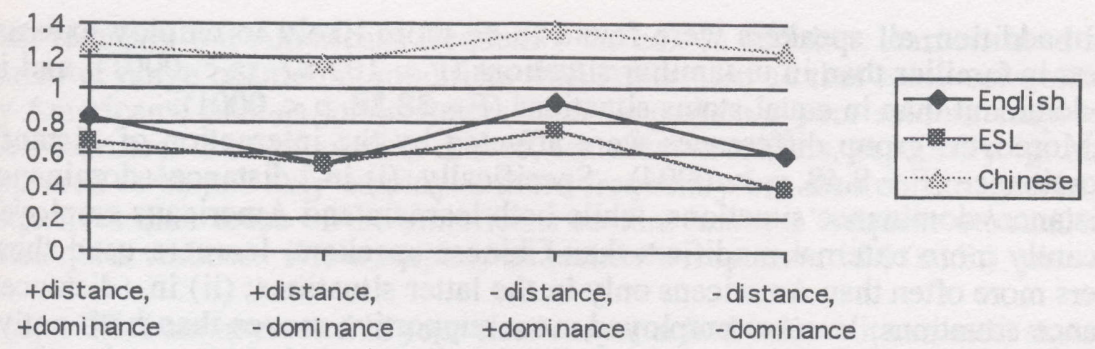

Figure 6. Rate of use of downgraders by group and speaker-listener attributes.

\subsubsection{External modifiers}

Analyses of variance were again used to examine the effects of 'group', 'distance', and 'dominance' on the subjects' use of external modification. Table 11 shows the results for all speakers' overall use of supportive moves.

Table 11. Summary table for the subjects' overall use of supportive moves.

\begin{tabular}{|c|c|c|c|c|c|}
\hline Source of variance & $\begin{array}{c}\text { Degrees of } \\
\text { freedom }\end{array}$ & $\begin{array}{l}\text { Sum of } \\
\text { squares }\end{array}$ & $\begin{array}{c}\text { Mean } \\
\text { squares }\end{array}$ & F statistic & pvalue \\
\hline \multicolumn{6}{|c|}{ Between-subjects effect } \\
\hline GROUP & 2 & 28.47 & 14.23 & 24.04 & $.0001^{* * *}$ \\
\hline $\begin{array}{c}\text { Error } \\
\text { Within-subjects effect }\end{array}$ & 117 & 69.28 & .59 & & \\
\hline DISTANCE & 1 & 34.67 & 34.67 & 102.87 & $.0001^{* * *}$ \\
\hline DISTANCE $x$ GROUP & 2 & 2.15 & 1.08 & 3.19 & $.0448^{*}$ \\
\hline Error (DISTANCE) & 117 & 39.43 & .34 & & \\
\hline DOMINANCE & 1 & 13.67 & 13.67 & 38.28 & $.0001^{* * *}$ \\
\hline DOMINANCE X GROUP & 2 & .80 & .40 & 1.12 & .3297 \\
\hline Error (DOMINANCE) & 117 & 41.78 & .36 & & \\
\hline $\begin{array}{l}\text { DISTANCE } \mathrm{x} \\
\text { DOMINANCE }\end{array}$ & 1 & .10 & .10 & .30 & .5831 \\
\hline $\begin{array}{l}\text { DISTANCE } x \\
\text { X }\end{array}$ & 2 & 5.72 & 2.86 & 8.48 & $.0004^{* * *}$ \\
\hline $\begin{array}{l}\text { DOMINANCE X GROUP } \\
\text { Error (DISTANCE x } \\
\text { DOMINANCE) }\end{array}$ & 117 & 39.43 & .34 & & \\
\hline
\end{tabular}

As Table 11 displays, the three groups used external modifiers differently ( $\mathrm{F}$ $=24.04, \mathrm{p}<.0001$ ). Post hoc Tukey tests showed that learners used significantly more supportive moves than both Americans and Chinese speakers $(\mathrm{p}<.05)$. 
In addition, all speakers were found to be more likely to employ external modifiers in familiar than in unfamiliar situations $(\mathrm{F}=102.87, \mathrm{p}<.0001)$, and in hearer-dominant than in equal-status situations $(\mathrm{F}=38.28, \mathrm{p}<.0001)$.

Moreover, group differences were affected by the interaction of distance with dominance $(\mathrm{F}=8.48, \mathrm{p}<.0004)$. Specifically, (i) in +distance/+dominance and -distance/-dominance situations, while both learners and Americans employed significantly more external modifiers than Chinese speakers, learners used these modifiers more often than Americans only in the latter situations; (ii) in +distance/dominance situations, learners employed more supportive moves than both native Chinese speakers and English speakers; (iii) in -distance/+dominance situations, both learners and native Chinese speakers used these modifiers more often than Americans. Table 12 and Figure 7 summarize this interaction effect.

Table 12. Summary table of the distance by dominance effect on the differences of the three groups' use of external modifiers.

English ESL Chinese

DISTANCE

\begin{tabular}{rrrrr} 
& $\begin{array}{c}\text { DOMINANCE } \\
+\end{array}$ & $1.03(\mathrm{~A})^{*}$ & $1.19(\mathrm{~A})$ & $.79(\mathrm{~B})$ \\
& - & $.78(\mathrm{~B})$ & $.98(\mathrm{~A})$ & $.70(\mathrm{~B})$ \\
\hline- & + & $1.09(\mathrm{~B})$ & $1.40(\mathrm{~A})$ & $1.28(\mathrm{~A})$ \\
$*$ & - & $1.10(\mathrm{~B})$ & $1.28(\mathrm{~A})$ & $.93(\mathrm{C})$
\end{tabular}

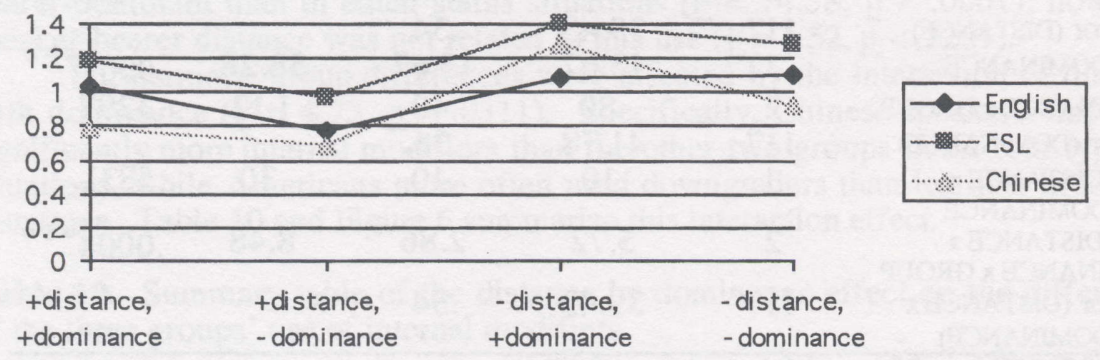

Figure 7. Rate of use of external modification by group and speaker-listener attributes.

\section{- Qualitative Analyses}

\subsubsection{Use of internal and external modifiers}

The quantitative findings above show that learners' modifier use differed from that of the Americans. The examination of their responses can offer further insights into this issue. For downgraders, as mentioned before, rarely did learners employ past tense forms of verbs or modal verbs to mitigate the imposing force of 
their requests, but Americans frequently did so. In addition, learners used a much narrower range of internal modifiers than Americans so that some categories used by Americans, such as 'understaters' and 'appealers', were seldom employed by ESL learners. For supportive moves, learners' modifiers, especially 'grounders', appeared to be not only employed more frequently but also constructed in longer sequences than those of the Americans so that learners' request utterances were often quite verbose. For example, one learner's response to S6 (audit) was

(8) ' $\mathrm{Hi}$, I am interested in your class very much. I believe it can meet my interests and purposes. Also, I'm sure your class would help me develop some ideas for my study. So I think your class will certainly be of big help to me. So I hope you can allow me to audit your class. I'll be really, really very appreciated.' (S6: audit)

This performance of learners suggests that they might have overshot the target language norms.

In this study, both learners and native Chinese speakers were found to use many more politeness markers and subjectivizers than English speakers. This may again suggest that learners might appropriate politeness strategies from their L1 and translate them into English forms. For example, Chinese speakers frequently express their politeness by using '请 qing' (ask), a politeness marker, when making requests to someone with an equal status who the speaker thinks is not close to $\mathrm{him} /$ herself and/or to someone with a higher social status than the speaker. This practice was also observed in learners' performance. Also, learners, like Chinese speakers, used want statements with 'subjectivizers' like '我希望 wǒ xīwàng' (I hope) to show politeness in many situations, but seldom did English speakers use this kind of expression in the present study. Further, some learners were found to use English forms of the characteristic Chinese external modifiers such as '真抱兼 zhēnbaòqian' (I'm very sorry) or '对不起 duibùq'̌' (I'm sorry) before issuing a request. For example,

\section{(9) 'I'm sorry. Can I ask you to help me move my desk?'9 (S3: desk).}

In contrast, this kind of formulaic apology expression, which is usually intended by speakers to show politeness by apologizing for the trouble that their requests may cause to hearers, was never observed in the American request sequences of this or other studies 10 .

Evidence of L1-L2 relatedness in the use of external modifiers can also be seen from 'information sequencing' in discourse. Studies on this area in Chinese requests have shown that while Westerners use the grounder most often after the request has been issued, Chinese speakers employ it most frequently before the core request (Kirkpatrick, 1991; Zhang, 1995). This difference between Chinese and Western discourse styles was also observed in this study; in addition, learners, like Chinese using Chinese, were found to employ grounders most often before their requests, which again suggests that learners' performance in L2 was related to their L1 style. 


\subsubsection{Influence of contextual factors}

The result that there is a main effect for dominance in internal and external modifiers and for distance in supportive moves (Table 9 and 11) suggests that all subjects' use of these two types of modifiers differed across social variables. In addition, subjects' performance in two situations designed to represent the same social relations sometimes appears to differ greatly. Take Situation 3 (desk) and 4 (photo) for example, Americans' external modifier frequency per request was 1.20 in S3 and 0.35 in S4, native Chinese speakers' was 1.10 in S3 and 0.30 in S4, and ESL learners' was 1.43 in S3 and 0.53 in S4. As noted above, speakers' speech act behavior has been argued to be affected by three contextual factors: distance, dominance, and ranking of imposition (Brown \& Levinson, 1978, 1987). Since in the two situations with the same constraints, it is distance and dominance that are set up to be the same, this differentiated performance of each group may have to do with its specific evaluation of imposition and/or other contextual factors. For instance, the analysis above has suggested that when the degree of imposition is considered high by speakers, it is likely that they would tend to employ supportive moves and/or downgraders to show politeness in order to increase the chance of having their request carried out.

These results and analyses suggest that Chinese ESL learners also differed from native English speakers in their use of modifiers. The former had a higher frequency of supportive moves per request than the latter, but displayed a lower frequency of downgraders per request. Further, learners' internal and external modifiers showed some similarities with those of Chinese L1 speakers, especially the use of politeness markers, subjectivizers, information sequences, and formulaic apologies. In addition, subjects did differ in their use of modifiers across social factors, and evidently the evaluation of imposition and/or other variables affected their modifier use, causing their performance to differ substantially even across situations representing the same social relations.

\section{DISCUSSION}

The results from this study indicated that in making requests, Chinese ESL learners, like Chinese using Chinese, were more direct than English speakers. In this section, directness issue for Chinese speakers will be first discussed, and then this issue will be addressed from the perspectives of universality versus culturespecificity in speech act performance.

\subsection{Directness and indirectness in Chinese}

While the results above show that compared to English speakers, Chinese speakers employ more direct strategies in making requests, there are two reasons why the Chinese relative directness deserves closer inspection. First, their direct forms sometimes seem to combine both direct and indirect elements. For example, as noted above, many of their direct forms were issued via 'want statements'. This kind of Chinese direct strategy was frequently expressed through an 'I hope that . ..' type of utterance, in which the hope expressed is itself a conventionally indirect request that refers to the hearer's ability or willingness, such as 
(10) 'I hope that you can let me take the exam some time later.' (S5: exam)

In comparison with other 'want statement' direct forms like

(11) 'I'd like to audit your class.' (S6: audit)

the 'I hope that ...' type appears to be much more indirect.

Second, there seem to be conceptual differences of directness/indirectness between native Chinese and English speakers. While the nine substrategies used by Blum-Kulka et al. (1989) to distinguish directness and indirectness seem to be valid in English, based on Zhang's (1995) interview data and the investigator's pilot work, Chinese usually tend to consider these substrategies, when presented as single utterances, equally direct-though they may differ in politeness degree. For Chinese, indirectness is generally realized through downgraders and also at the discourse level, either through supportive moves or through 'small talk', e.g., "conversation on topics other than those related to the intended action" (Zhang, 1995, p. 82). Furthermore, Chinese indirectness can be accomplished through information sequencing, that is, through prefacing one's intended request with small talk or supportive moves. According to Chinese norms, the more one uses this kind of talk or moves, the more indirect one's speech appears to be. Thus, indirectness in Chinese discourse tends to consist of a 'because . . . therefore' structure, rather than a 'therefore . . . because' structure (Kirkpatrick, 1991).

The linguistic indirectness manifested in small talk or supportive moves plays a very crucial role in Chinese politeness and face concerns. As mentioned above, Chinese face places much emphasis on the communal character and social orientation of face. This emphasis makes the interactional dynamics of Chinese facework appear reciprocal, with both interlocutors "engaged in mutually shared orientation to negotiate, elevate, and attend to each other's face" (Zhang, 1995, p. 85). To be polite, thus, is to observe each other's face. For Chinese, resorting to small talk or supportive moves is a strategy by which all parties can constantly assess ongoing conversation so as to make appropriate face adjustments to each other if necessary. Small talk or supportive moves can help both speaker and hearer observe the mood and attitude of each other, thus fine-tuning the face distance and relationship between them and generating a harmonious atmosphere to conduct transactions. With this kind of interactive adjustment, the balance of face between interactants can thus be achieved (Scollon \& Wong-Scollon, 1991, Zhang, 1995).

Accordingly, contrary to Færch and Kasper's (1989) claim that external modification is only optional in realizing indirectness for English, German, and Danish speakers, Chinese indirectness cannot be really perceived without small talk or supportive moves preceding the request. Hence, the present finding that most Chinese supportive moves precede the core request suggests that this may be actually the way in which Chinese speakers express their indirectness.

However, the result that Chinese speakers used more direct forms did not necessarily mean that they were less polite. First, most Chinese direct requests were modified through internal modifiers like '您 nín' (the honorific second person 
pronominal) and/or politeness markers such as '请 qing' (ask). Second, their direct strategies in hearer-dominant, unfamiliar, or seemingly high imposition situations, in addition to including downgraders, were also usually modified through lengthy supportive moves, which suggests that under these circumstances, they tended to feel a need to show their indirectness. Thus, for Chinese, direct requests can also be polite.

More importantly, one caveat is in order here. The broad picture presented in this paper may need to be qualified by the fact that the situations examined were those in which the speaker was not dominant over the hearer. Also, this study only included two situations for each combination of the contextual variables studied. As other factors would affect the speaker's performance, it is very likely that we cannot get a complete picture of a given group's speech act pattern only from the two situations studied here. As a result, we may actually observe much greater cross-linguistic variation if speaker-dominant situations are included or if more situations are included for each type of social relation.

\subsection{Universality versus Culture-Specificity}

When it comes to the performance of speech acts, the issue of universality versus culture-specificity is of great interest to pragmatists. Some scholars have claimed that speech acts operate by universal principles of politeness, in which a general mechanism motivates speakers to phrase their utterances indirectly and/or with mitigating devices (Austin, 1962; Searle, 1969, 1975; Leech, 1983). Further, it is contended that the strategies for realizing specific speech acts are essentially identical across cultures and languages, though the appropriate use of any given strategy may not be exactly the same across different speech communities (Fraser, 1985). By contrast, others have argued that speech acts vary in conception and expression across languages, and that their modes of performance are primarily motivated by differences in cultural norms and assumptions (Green, 1975; BlumKulka, House, \& Kasper, 1989). Also, it is even suggested that any universality claims in speech act performance are nothing but subjective, ethnocentric AngloSaxon perspectives (Wierzbicka, 1991).

With respect to requests, they have been referred to as face-threatening acts in that the imposition accompanied by them is considered costly to the hearer so as to constitute a threat to the addressee's negative face wants to be left alone (Brown \& Levinson, 1978, 1987). Rationally, the speaker, while minding causing the hearer trouble from his/her request, would still like to have the request carried out; thus s/he would try to mitigate his/her threat to the hearer and simultaneously pursue the request goal. Accordingly, proponents of the universality thesis claim that to fulfill these dual tasks, the speaker would prefer using indirect forms and modifiers because they could appear more polite by doing so. Indirect language use is thus considered to be mainly motivated by politeness. For example, Leech (1983) argues that "indirect illocutions tend to be more polite (a) because they increase the degree of optionality, and (b) because the more indirect an illocution is, the more diminished and tentative its force tends to be" (p. 108). Based upon the result of the present study, indirectness is indeed manifested for all groups, which basically supports the universality of indirect speech acts. 
However, the evidence from this study fits the universality thesis in only a very general and imperfect manner. For instance, Searle (1975) formulates several universal generalizations for indirect requests, such as that one can issue a request by stating that the preparatory condition holds (e.g., 'You can sit'), but some of them, such as the one above, do not hold in Chinese. Also, whereas the parallel relationship between politeness and indirectness has been considered a universal pattern of language use, this relationship has been empirically demonstrated to be non-linear by studies of speech act perception. These studies have shown that it is conventional indirectness, not nonconventional indirectness, that is rated as the optimal strategy by speakers of many different languages, such as British English and German (House, 1986), American English and Israeli Hebrew (Blum-Kulka, 1987). Blum-Kulka's Israeli subjects even regarded directness as the next optimal strategy.

To explain why the speaker prefers conventional indirectness, Blum-Kulka (1987) contends that politeness can be viewed as motivated both by the need to minimize the threat to face and the need to adhere to pragmatic clarity, and that the highest level of politeness is achieved via this type of indirectness in that both needs can be satisfied simultaneously. In other words, politeness is derived from the interactional balance between both needs. Thus, tipping the balance in favor of either noncoerciveness (as in the case of nonconventionally indirect strategies) or pragmatic clarity (as in the case of direct forms) might be perceived as impolite. The fact that most production studies of requests demonstrate that subjects prefer conventional indirectness appears to lend support to Blum-Kulka's and House's argument that it is the optimal strategy in issuing requests.

In practice, there have been problems in applying the universality claim to other languages and cultures, and some scholars suspect that this claim is "more biased by the English examples analyzed than warranted by the theory" (BlumKulka, 1989, p. 64). For example, Wierzbicka (1991) argues that most pragmatic theories of universality are based solely upon the Anglo-Saxon tradition "which places special emphasis on the rights and on the autonomy of every individual, which abhors interference in other people's affairs (It's none of my business), which is tolerant of individual idiosyncrasies and peculiarities, which respects everyone's privacy" (p. 30). Hence, these theories do not work when applied to many other societies. With this kind of cultural belief, English speakers generally tend to avoid using direct forms in many situations in that being direct contradicts their underlying cultural values and could be seen as impolite (Blum-Kulka, 1987; Blum-Kulka \& House, 1989).

In contrast, the Chinese sociocultural context traditionally legitimizes a vertical class structure following Confucian political philosophy that stresses respect and subordination to the authorities (Oliver, 1971). Thus, there has been a high value placed on communal needs over individual preferences. According to Brown and Levinson $(1978,1987)$, Chinese cultural norms place greater emphasis on positive politeness (or solidarity politeness, in Scollon \& Scollon's term, 1983), the desire for social approval, rather than negative politeness, the desire to be left alone. Whereas politeness for Westerners is basically associated with negative politeness, Chinese tend to see this type of politeness as irrelevant in contexts where being direct is socially appropriate. For requesting, indirectness can be 
deemed as inappropriate (i) when requests are considered to be easily carried out, (ii) when interlocutors are close to one another, and (iii) when the speaker is in a position of authority or power (Lee-Wong, 1994). Under these circumstances, Chinese cultural beliefs generally encourage a communicative style that prefers explicit, clear, and concise linguistic conventions in order to convey speakers' attitude of upfront sincerity (Oliver, 1971).

Take for example utterances (A) 'Please take a picture for us' and (B) 'Could you take a picture for us?'. Usually Chinese would think it strange for a speaker, wanting the addressee to do something, to ask if the addressee can do so-especially under the three circumstances above. So they prefer using (A) because (B) clashes with their sincerity. From the Chinese viewpoint, a direct request like (A) is socially acceptable, sincere, and polite, whereas for Westerners, it may be perceived as impolite or even rude (Lee-Wong, 1994). As speech act behavior is closely related to the speaker's cultural values, it is understandable that Chinese speakers would prefer using direct forms in many situations because for them, being direct can display the speaker's attitude of sincerity and optimism concerning the addressee's willingness to comply, and thus be regarded as polite. Therefore, while all groups in this study manifested a preference for conventional indirectness, which appears to be in accordance with Blum-Kulka's 'interactional balance' argument above, the relative directness of both Chinese groups can be explained by their cultural norms, i.e., in some situations, their concern for clarity and sincerity and their optimism about hearer's good will legitimize a conscious suspension of negative face-maintaining considerations. So we find that whereas for Americans, conventional indirectness appears to be a norm prevailing in most social interactions, for Chinese, it is not, in that their strategy use is likely to be based on a complex interaction among the dimensions of different social factors.

The complexity of Chinese strategy choice can be further illustrated by the finding in this study that the two Chinese groups were overall more likely to use direct strategies in hearer-dominant than in equal-status situations. The direct forms they used in hearer-dominant situations were never the 'mood derivable' substrategy like the imperative, but often the want statement such as ' $I$ hope you can ... - especially when the degree of imposition seemed high (as the examples (7) and (8)). This type of direct sequence was usually neither explicit nor concise; rather, it often appeared lengthy because of many downgraders and supportive moves attached. By employing the 'I hope' kind of request to the hearer with a higher social status than the speaker, Chinese seem to use ' $I$ hope' as a framing routine formula and then assume that the addressee would be willing to help them out. This assumption may reflect Chinese emphasis on solidarity politeness in that to meet the expectations of communal norms and thus enhance one's own face, the powerful addressee is supposed to give face to the speaker by honoring the request, while the speaker is supposed to give face to the addressee by showing respect. We therefore found that in the 'I hope' sequence, the speaker not only referred to the hearer's ability or willingness, but also used lots of modifiers to the request with the result that a long, but highly mitigated, very polite request was produced.

To further reveal the vital role that culture plays in speech act performance, it is worth noting that there exists a similar direct tendency in Israeli politeness 
behavior (Blum-Kulka, Danet, \& Gherson, 1985; Blum-Kulka, 1987). According to Blum-Kulka, the Israeli relatively high level of directness is motivated by their cultural background that lays special emphasis on an ideology of egalitarianism and hence attributes high value to sincerity and simplicity in speech, which have both been shown to be positively associated with the notion of dugri (i.e., direct, straight) talk (Katriel, 1986). Therefore, Israeli requestive behavior, like Chinese, also confirms Scollon and Scollon's (1983) claim that direct strategies constitute a part of a solidarity politeness system. We thus see that while the surface behavior of both cultures is similar, the underlying norms justifying their preferences are quite distinct.

The implication of this study that for Chinese, being direct can be polite obviously challenges the claim to universality concerning the parallel relationship between indirectness and politeness. In fact, in addition to the perception studies mentioned earlier on, politeness research in non-English speaking societies has provided evidence to question this claim as well. For example, Blum-Kulka's $(1983,1985)$ research on Hebrew, Matsumoto's $(1988,1989)$ on Japanese, Gu's (1990) and Lee-Wong's (1994) on Chinese, Wierzbicka's (1991) on Polish, and Mir's (1993) on Peninsular Spanish all indicated that in many situations, it is a direct request, not an indirect one, that is considered the optimal strategy. Hence, cross-cultural studies appear to show that the traditional claim that directness is not compatible with politeness cannot be held anymore, and that this non-parallel relationship is influenced by "the discourse domain, the social context where interaction takes place, and more importantly, the interlocutors' cultural values" (Mir, 1993, p. 4).

Therefore, in addition to a broad accordance with the claim to universality, the results of the present study apparently support Wierzbicka's (1991) argument that "different cultures find expression in different systems of speech acts, and that different speech acts become entrenched, and, to some extent, codified in different languages" (p. 26). Hence, although this study does indicate that there are some general shared concepts and dimensions of politeness across all groups, differences in the proportion of the strategies and modifiers employed reveal what role culture may play on its speakers' speech act performance. These differences have to do with a culture's ethos and its own specific way of speaking (Hymes, 1974). Indeed, speakers of a given culture have been shown to have mutually shared expectations about what the appropriate behavior and its social meanings are in different contexts (Blum-Kulka, 1987). For requesting, the expectation in Western culture seems to be standardized so that speakers will primarily use conventional indirectness in their requests, but the expectation in Chinese and Israeli societies, which attach a high value to clarity and sincerity in speech, is less homogeneous so that their members may find conventional indirectness inappropriate, especially in situations which they think do not really call for indirectness (Blum-Kulka, 1989). Consequently, we can further see how cultural norms and attitudes intervene in determining the distinctive patterns of requestive behavior.

\subsection{Conclusions and Implications}

The aim of this study is to investigate whether different language groups may typically manifest different requestive behavior at the pragmatic level. By 
examining the speech act of requests in varying contexts, this paper reveals that the ability to issue requests appropriately in different contexts is a challenging task for L2 learners. In fact, this ability is an indispensable aspect of communicative competence that cannot be treated lightly as it assists learners in interpreting what is meant by what is said to them, and in gaining control over the way in which they interact with the target language speakers (Wolfson, 1989).

Specifically, the findings of the present study have practical educational implications for L2 learning and teaching. First, L2 learners may need to better understand pragmatic aspects of the target culture in order to approximate native speakers' behavior. Second, L2 teachers may need to include more cross-cultural pragmatic analyses in their teaching to address learners' communicative problems. In other words, through well-planned education that focuses more on the cultural meanings underlying speech act behavior, teachers can help students raise their sociolinguistic consciousness and thus aid them to success of their L2 acquisition.

\section{FOOTNOTES}

1. This paper is based on my Qualifying Paper (1997) done at Harvard Graduate School of Education. I am very grateful to Professor Catherine E. Snow and Dr. Barbara Alexander Pan for their constructive comments. In particular, I am indebted to Professor Lowry Hemphill, my advisor, for her insightful suggestions and warm support. In addition, I want to thank the IPrA referee, whose comments and criticism are very helpful to the revision of the present essay. I, of course, am solely responsible for all the errors that may remain.

2. Throughout this paper, 'Chinese' refers to 'Mandarin', which is based on the Beijing dialect and is the official language used in the People's Republic of China (PRC) and the Republic of China on Taiwan (ROC). In the PRC, Mandarin is called '普通话 pŭtōnghuà' (common language), while in the ROC, it is called '国语 guóyǔ' (national language). Basically, both '普通话 pǔtōnghuà' and '国语 guóyǔ' are very similar except in a few areas of morphology and phonology (Li \& Thompson, 1981).

3. Throughout the paper, all Chinese characters are transliterated into romanization following the Pinyin system, which is the official transcription system used in the PRC and is very much widely adopted in scholarly writings on Chinese in the West (Li \& Thompson, 1981).

4. The DCT questionnaire includes a number of situational descriptions, followed by a slot in which subjects have to provide the appropriate linguistic form of the speech act studied-as if they are the speakers in real-life interactions. The questionnaire used in this study is in the Appendix. 
5. In this study, internal modifiers are considered optional items serving to soften the imposing force of a request. They can be divided into two types: (i) syntactic downgraders, which refer to the devices that modify the request utterance internally by mitigating its imposing force via syntactic choice. For example, the requestive force of the utterance ' $I$ was wondering if you could help me move it' is modified through the conditional clause, an internal syntactic structure used to make a request; (ii) lexical/phrasal downgraders, which refer to the optional additions that modify the request utterance internally through lexical/phrasal choice in order to mitigate its imposing force. For example, the requestive force of the utterance 'Could you please open the door for me?' is modified through the politeness marker 'please', a lexical element added internally to the request. On the other hand, external modifiers are considered optional elements serving to mitigate the imposing force of a request. They, generally referred to as 'supportive moves', are external to the request utterance, occurring either before or after it. For example, the requestive force of the utterance ' $I$ ' $d$ like to discuss something with you. I was thinking maybe we could meet together after class' is modified by the part 'I'd like to discuss something with you'.

6. The interrater agreement results for strategies, downgraders, and supportive moves were $100 \%, 91 \%$, and $96 \%$ respectively for the native English data, $98 \%$, $93 \%$, and $94 \%$ respectively for the learner data, and $95 \%, 90 \%, 93 \%$ respectively for the Chinese data.

7. In this section, request strategies and modifiers are addressed separately in that the coding scheme chosen in the present study and the analytic strategy used, which closely follow those of the CCSARP conducted by Blum-Kulka, House, and Kasper (1989), do not allow this study to do statistical analyses to consider strategies and modifiers in combination. It is indeed likely that the total effect of the subjects' response would be missed by not taking account of the request and its accompanying modifiers together at some point. Thus, to get a bit closer to the complete picture of the subjects' requestive behavior, the combination of strategies and modifiers is discussed qualitatively in the Discussion section.

8. "S1: class", "S2: door", "S3: desk", "S4: photo", "S5: exam", "S6: audit", "S7: study", and "S8: notes" refer to Situation $1,2,3,4,5,6,7$, and 8 respectively in the discourse completion questionnaire.

9. In this respect, the performance of Chinese ESL learners was similar to that of Japanese learners of English in Fukushima's (1990) study, who sometimes prefaced their requests with 'I'm sorry' (from Japanese such as 'gomennasai' or 'sumimasen') in some situations like Japanese L1 speakers.

10. It is a common practice for English speakers to use 'excuse me' before issuing a request; however, semantically it is not intended by the speaker to apologize for the trouble that his/her request may cause to the hearer (Fukushima, 1990; Kasper \& Blum-Kulka, 1993). 


\section{References}

Austin, J.L. (1962) How to do things with words. Cambridge, MA: Harvard University Press.

Beebe, L.M., and T. Takahashi (1989) Sociolinguistic variation in face-threatening speech acts: Chastisement and disagreement. In M.R. Eisenstein (ed.), The dynamic interlanguage: Empirical studies in second language variation. New York: Plenum., pp. 199-218.

Blom, J., and J. Gumperz (1972) Social meaning in linguistic structures: Code-switching in Norway. In J. Gumperz \& D. Hymes (eds.), Directions in sociolinguistics. New York: Holt, Rinehart, \& Winston, pp. 407-34.

Blum-Kulka, S. (1983) Interpreting and performing speech acts in a second language: A cross-cultural study of Hebrew and English. In N. Wolfson \& E. Judd (eds.), Sociolinguistics and language acquisition. Rowley, MA: Newbury House, pp. 36-55.

Blum-Kulka, S. (1985) The multifunctionality of discourse markers: The case of requests. Theoretical Linguistics 12: 213-29.

Blum-Kulka, S. (1987) Indirectness and politeness in requests: Same or different? Journal of Pragmatics 11: $131-46$.

Blum-Kulka, S. (1989) Playing it safe: The role of conventionality in indirectness. In S. Blum-Kulka, J. House, \& G. Kasper (eds.), Cross-cultural pragmatics: Requests and apologies. Norwood, NJ: Ablex., pp. $37-70$.

Blum-Kulka, S., B. Danet, and R. Gherson (1985) The language of requesting in Israeli society. In J. Forgas (ed.), Language and social situation. New York: Springer Verlag, pp. 113-141.

Blum-Kulka, S., and J. House (1989) Cross-cultural and situational variation in requesting behavior. In S. Blum-Kulka, J. House, \& G. Kasper (eds.), Cross-cultural pragmatics: Requests and apologies. Norwood, NJ: Ablex, pp. 123-173.

Blum-Kulka, S., J. House, and G. Kasper (1989) Cross-cultural pragmatics: Requests and apologies. Norwood, NJ: Ablex.

Brown, P., and S. Levinson (1978) Universals of language usage: Politeness Phenomena. In E. Goody (ed.), Questions and politeness. Cambridge: Cambridge University Press, pp. 56-234.

Brown, P., and S. Levinson (1987) Politeness: Some universals in language usage. Cambridge: Cambridge University Press.

Clyne, M., M. Ball, and D. Neil (1991) Intercultural communication at work in Australia: Complaints and apologies in turns. Multilingua 10: 251-73.

Cohen, J. (1960) A coefficient of agreement for nominal scales. Educational Psychological Measurement 20: $37-46$.

Færch, C, and G. Kasper (1989) Internal and external modification in interlanguage request realization. In S. Blum-Kulka, J. House, \& G. Kasper (eds.), Cross-cultural pragmatics: Requests and apologies. Norwood, NJ: Ablex, pp. 221-247.

Fraser, B. (1985) On the universality of speech act strategies. In S. George (ed.), From the linguistic to the social context. Bologna, Italy: CLUEB, pp. 43-49. 
Fukushima, S. (1990) Offers and requests: Performance by Japanese learners of English. World Englishes 9: $317-25$.

Green, G. (1975) How to get people to do things with words. In P. Cole \& J. Morgan (eds.), Syntax and semantics 3: Speech acts. New York: Academic Press, pp. 107-142.

Grice, H.P. (1975) Logic and conversation. In P. Cole \& J. Morgan (eds.), Syntax and semantics, vol. 3: Speech acts. New York: Academic Press, pp. 41-58.

Gu, Y. (1990) Politeness phenomena in modern Chinese. Journal of Pragmatics 14. 2: 237-57.

Gumperz, J.J. (1982) Discourse strategies. Cambridge: Cambridge University Press.

Ho, D.Y. (1975) On the concept of face. American Journal of Sociology 81.4: 867-84.

House, J. (1986) Cross-cultural pragmatics and foreign language teaching. In Seminar für Sprachlehrforschung der Ruhr-Universität Bochum (ed.), Probleme und Perspektiven der Sprachlehrforschung. Frankfurt, Germany: Scriptor, pp. 281-295.

Hu, H.C. (1944) The Chinese concept of "face". American Anthropologist 46: 45-65.

Hymes, D. (1974) Foundation in sociolinguistics: An ethnographic approach. Philadelphia: University of Pennsylvania Press.

Katriel, T. (1986) Talking straight: Dugri speech in Israeli Sabra culture. London: Cambridge University Press.

Kasper, G., and S. Blum-Kulka (1993) Interlanguage pragmatics. New York: Oxford University Press.

Kasper, G., and M. Dahl(1991) Research methods in interlanguage pragmatics. Second Language Teaching and Curriculum Center, Honolulu, HI: University of Hawaiï Press.

Kirkpatrick, A. (1991) Information sequencing in Mandarin in letters of request. Anthropological Linguistics 33.2: $183-203$.

Leech, G.N. (1983). Principles of pragmatics. New York: Longman.

Lee-Wong, S.M. (1994) Imperatives in requests: Direct or impolite observations from Chinese. Pragmatics 4.4: $491-515$.

Li, C., and S. Thompson (1981) Mandarin Chinese: A functional reference grammar. Berkeley, CA: University of California Press.

Mao, L. (1994) Beyond politeness theory: "Face" revisited and reviewed. Journal of Pragmatics 21.5: 451486.

Matsumoto, Y.(1988) Reexamination of the universality of face: Politeness phenomena in Japanese. Journal of Pragmatics 12: 403-426.

Matsumoto, Y. (1989) Politeness and conversational universals: Observations from Japanese. Multilingua 8: $207-21$.

Mir, M. (1993) Direct request can also be polite. Paper presented at the Annual Meeting of the International Conference on Pragmatics and Language Learning, 7th, Champaign, IL, April 1-3. 
Oliver, R.T. (1971) Communication and culture in ancient India and China. New York: Syracuse University Press.

Scollon, R., and S. Scollon (1983) Face in interethnic communication. In I.C. Richards \& R.W. Schmidt (eds.), Language and communication. London: Longman, pp. 156-188.

Scollon, R., and S. Wong-Scollon (1991) Topic confusion in English-Asian discourse. World Englishes 9: 113-123.

Searle, J.R. (1969) Speech acts: An essay in the philosophy of language. Cambridge: Cambridge University Press.

Searle, J.R. (1975) Indirect speech acts. In P. Cole \& J. Morgan (eds.), Syntax and semantics, 3: Speech acts. New York: Academic Press, pp. 59-82.

Wierzbicka, A. (1991) Cross-cultural pragmatics: The semantics of human interaction. Berlin: Mouton de Gruyter.

Wolfson, N. (1989) Perspectives: Sociolinguistics and TESOL. New York: Newbury House.

Wolfson, N., L. D'Amico-Reisner, and L. Huber (1983) How to arrange for social commitments in American English: The invitation. In N. Wolfson \& E. Judd (eds.), Sociolinguistics and language acquisition. Rowley, MA: Newbury House, pp. 116-128.

Zhang, Y. (1995) Indirectness in Chinese requesting. In G. Kasper (ed.), Pragmatics of Chinese as native and target language. Second Language Teaching and Curriculum Center, Honolulu, HI: University of Hawaii Press, pp. 69-118. 


\section{APPENDIX: DISCOURSE COMPLETION TASK}

Situation 1 (+distance; +dominance)*

You are very much interested in taking a course but you notice that this course requires certain academic background as a prerequisite. Although you don't meet this prerequisite and you don't already know the instructor, you decide to try to ask the instructor to allow you to take this course. What would you say to get this instructor to grant you permission to participate in this course?

Situation 2 (+distance; +dominance)

You are on your way out of a school building and your hands are both so full that you need someone to open the door for you. You notice that a professor whom you don't really know (you know this person is a professor, but you have never spoken to this professor or took this professor's class) is standing nearby the door, and you see no other people near you. So you decide to ask this professor to open the door for you. What would you say to get this professor to do this favor for you?

Situation 3 (+distance; -dominance)

You are moving into a dorm and want to move your oak desk into your new room, but you find it too heavy to move it on your own. You have no friends nearby, so you decide to knock on your new neighbor's door to ask for help. What would you say to get this new neighbor to give you a hand moving your desk?

Situation 4 (+distance; -dominance)

A friend of yours from out of town is paying you a visit. You are showing your friend around the campus and both of you would like to take a photo together to remember this happy moment, so you decide to ask a nearby student whom you don't know to do you this favor. What would you say to get this student to take your picture together?

Situation 5 (-distance; +dominance)

Your final exams are approaching and you find that the scheduled date of one subject is the same date as that of your brother's wedding. You cannot do both in that day and you prefer to join this unforgettable moment of your family, so you decide to ask your professor to rearrange another day especially for you to take this final. What would you say to get your professor to allow you to take the exam on another day?

* The combination of the binary-valued contextual variables-distance and dominance-embedded in each situation is specified with parentheses, which are intended only for readers' information and are not shown to subjects. '+distance' indicates that interlocutors do not already know each other, while '-distance' indicates that interlocutors know each other. '+dominance' means that the hearer is higher status, while '-dominance' indicates that interlocutors are equal status. 
Situation 6 (-distance; +dominance)

You are very much interested in auditing one class taught by a professor whom you have studied with before. So you decide to ask this professor's permission to audit. What would you say to get this professor to allow you to audit this class?

Situation 7 (-distance; -dominance)

You are preparing for upcoming midterms and find that some topics in the course are really difficult for you. A fellow student seems to understand the class much better than you. So you decide to ask this fellow student to help you get ready for the exam. What would you say to get this student to help you out?

Situation 8 (-distance; -dominance)

You missed one of the classes in a course you are enrolled in, so you decide to borrow a fellow student's notes to catch up with the rest of the class. What would you say to get this student to lend you notes for the class you missed? 